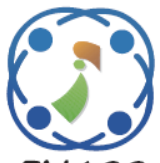

\title{
The Measurement of Consumer Interest and Prediction of Product Selection in E-commerce Using Eye Tracking Method
}

\author{
Juni Nurma Sari ${ }^{1,2 *} \quad$ Lukito Edi Nugroho $^{1} \quad$ Paulus Insap Santosa $^{1} \quad$ Ridi Ferdiana $^{1}$ \\ ${ }^{1}$ Electrical Engineering and Information Technology Department, \\ Universitas Gadjah Mada, Jogjakarta, Indonesia \\ ${ }^{2}$ Informatics Engineering Department, Politeknik Caltex Riau, Pekanbaru, Indonesia \\ * Corresponding author's Email: juni.s3te14@ mail.ugm.ac.id
}

\begin{abstract}
Consumer interest in products is recognized after the consumer buys products and provides a rating on it. Development of technology can get consumer interest in products through eyes. The technology used is eye tracking using eye tracker tool. Attraction Measurement is used to measure consumer interest. This method can be used to recognize attractive product display and measure consumers preference and consumers emotions in products. In this study, an experiment was conducted to determine consumer interest in the selva-house website with three products of hijabs. The study found that fixation duration can be used to recognize consumer interest in products. Another measurement is to determine whether consumers are willing to buy the products. The experiment results that consumer interest measurement and prediction of product selection measurement indicate that the second product is preferred by the consumers. This research shows that consumer interest model and prediction of product selection model, and the result of prediction measurement have a contribution to product recommendations for further research.
\end{abstract}

Keywords: Eye tracking measurement, Consumer interest, Prediction, Product selection.

\section{Introduction}

Development of internet technology affects human activities such as shopping. Shopping online has started being conducted through e-commerce. In e-commerce, there are catalogs containing products that will be sold. The first activity on online shopping is looking at existing catalogs, then comparing one product to others. The result of this activity is consumer interest in one of the products and seeing more details of the products. The next step is buying the product as a concrete step that the consumers are interested in. After purchasing, the consumers are usually asked to provide a rating [1] on the product to determine the level of consumer interest in it. Information level of consumer interest can be used as product recommendations to other consumers, to attract other consumers to buy the product. This is very helpful in the field of marketing to get new customers.
Another way to capture consumer interest is to get data browsing of consumer from weblog, namely clickstream data. With clickstream, the page that consumer see can also detect-how long consumer spends in that page. The lack of that method is the product that consumer prefers can not be detected, because there are many products shown in catalog.

The development of sensor technology makes it possible to know consumers interest in the product when consumers are browsing through catalogs. The technology is eye tracking technology which uses an eye tracker tool. Consumer's view of the product in the catalog can be detected with eye tracking method. Fixation duration, fixation count, and first time fixation are eye tracking data that can be used to find out consumer interest in a product. Some researches discuss the relation between consumer attention to the product and consumer selection to the same product. Fixation duration and fixation count used to detect consumer cognitive process to choose product with healthy GDA and GDA is in color and 
monochrome [2]; to detect the life style program that consumer wants. The life style program display on the text in ROI (Region on Interest) [3]; to detect what is the consumer favorit color on traditional food [4] and to detect the design of heavy meal that consumer prefer [5]. Based on those researches, fixation duration can also be used to identify prediction of product selection by consumers. When consumer chooses the product, it is assumed that consumer will purchase that product [6], then the prediction of product selection data can be treated as transaction data.

Furthermore, product recommendations require transaction data and rating data of product to produce the list of product that is recommended to buy. Using eye tracking technology, the consumer interest and the desire to buy product are the data that can be used for product recommendations described in Fig. 1. Therefore, this study discusses the measurement of consumer interest in the products by using the method of eye tracking; then it calculates the prediction of the consumer desire to buy the products. The contribution of this research is the model of consumer interest to product and the model of consumer prediction of product selection concerning the product recommendation.

Previous studies [7] used taxonomy classification of Aga Bojko using the eye tracking as a technology to determine consumer decisions, consumer interest, and web design towards the Aga Bojko taxonomy. In the taxonomy of Aga Bojko [8] measurements with the eye tracking method are divided into two categories: Attraction Measurement which is a measurement to determine the user's interest in the website and Performance Measurement which is a measurement to determine the quality of a website.

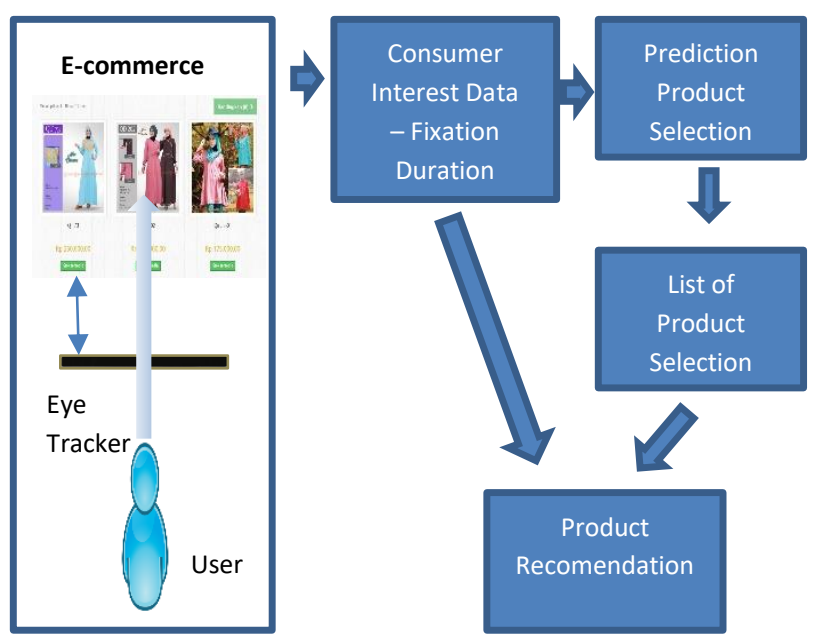

Figure.1 Consumer interest and prediction product selection for product recommendation
In this current study, the researchers discuss the measurement of consumer interest in e-commerce products using the taxonomy of Aga Bojko involving Attraction Measurement that consists of area noticeable measures, areas of interest measures and emotional arousal measures. Area noticeable measures determine which areas attract the attention of consumers, while Areas of interest measures identify areas preferred by the consumers and emotional arousal measures investigate the emotions of consumers of the products. The emotions of the consumers can be detected from the pupil of the eyes [9]. This study did not use the metric pupils, but it only used metrics fixation duration and fixation count. Thus, the experiments were conducted to analyze the area noticeable measures and the areas of interest measures.

Experiments were conducted using the website of selva-house which sells Muslim clothes and hijabs. The products used for the experiment were three hijabs. The calculation of product selection prediction is conducted by using eye tracking data which is fixation duration using Chandon method [10]. According to Chandon, the consumer interest in the product and experience in using a product or shopping experience will affect consumers in selecting products. The simulation of Chandon method also used the same website. The value of prediction converted to prediction level value. While the prediction level value is 4 , it means the product will be selected to buy by consumer. When consumer buys a product, the data transaction will be added to the database. Then data prediction of product selection can represent data transaction.

Discussions of the measurement of consumer interest and prediction selection in e-commerce product using eye tracking method are divided into several sections Section 2 discusses consumer interest in the e-commerce product and relation with product selection; section 3 discusses eye tracking method; section 4 discusses measurement method of eye tracking on consumer interest and prediction selection, and section 5 presents the discussion and conclusion.

\section{Consumer interest in the e-commerce products}

The development of internet technology suppose results in many emerging sites that help the daily lives of users, such as news site, social media sites and e-commerce, and so forth. Each site has different characteristics such as design and content. Each site provides personalized services, such as news sites, 
Table 1. Method to get consumer interest

\begin{tabular}{|c|c|c|c|}
\hline Focus & Method & Contribution & Limitation \\
\hline $\begin{array}{l}\text { Using user rating } \\
\text { behavior to build } \\
\text { binary model to } \\
\text { represent user } \\
\text { interest } \\
\text { Xiangyu Zhao, } \\
2013 \text { [1] }\end{array}$ & $\begin{array}{l}\text { Matching with user } \\
\text { interest then find } \\
\text { high quality item } \\
\text { that user will like }\end{array}$ & $\begin{array}{l}\text { A binary user model to } \\
\text { represent users' interests. }\end{array}$ & $\begin{array}{l}\text { User must interact with the system to } \\
\text { input rank of the movie. }\end{array}$ \\
\hline $\begin{array}{l}\text { Using clickstream } \\
\text { data to define user } \\
\text { interest pattern } \\
\text { Qiang Su, } 2015 \\
{[12]}\end{array}$ & $\begin{array}{l}\text { Clickstream data } \\
\text { detect consumer } \\
\text { behavior on visiting } \\
\text { sequence, } \\
\text { frequency and time } \\
\text { spent on each } \\
\text { category }\end{array}$ & $\begin{array}{l}\text { Improving the site's } \\
\text { recommendation strategies and } \\
\text { make the site more effective. }\end{array}$ & $\begin{array}{l}\text { The user interest can be known on each } \\
\text { category but not in product in catalog }\end{array}$ \\
\hline $\begin{array}{l}\text { Shopping } \\
\text { behaviour } \\
\text { analysis using eye } \\
\text { tracking and EEG } \\
\text { Piotr Chynal, } \\
2016[15]\end{array}$ & $\begin{array}{l}\text { Using eye tracking } \\
\text { to record eye gaze } \\
\text { and EEG to record } \\
\text { the emotion during } \\
\text { the process of } \\
\text { shopping. }\end{array}$ & $\begin{array}{l}\text { The eye tracking analysis can } \\
\text { find the order of shelf scanning } \\
\text { in accordance with the task. } \\
\text { The EEG analysis can find the } \\
\text { emotion of participant when } \\
\text { doing the task. }\end{array}$ & $\begin{array}{l}\text { EEG only capture the emotion of } \\
\text { frustation when doing the task. Eye } \\
\text { tracking can get the consumer attention } \\
\text { according to the task }\end{array}$ \\
\hline $\begin{array}{l}\text { Visual attention in } \\
\text { multiattribute } \\
\text { choice } \\
\text { Nicholas Krucien, } \\
2017 \text { [3] }\end{array}$ & $\begin{array}{l}\text { Choice experiment } \\
\text { and visual attention } \\
\text { (get by eye } \\
\text { tracking) }\end{array}$ & $\begin{array}{l}\text { There is relation between visual } \\
\text { attention (the metric is fixation } \\
\text { duration) and individuals' } \\
\text { preferences. }\end{array}$ & $\begin{array}{l}\text { With Choice Experiment, the subject } \\
\text { need more time to understand } \\
\text { complicated attribute. }\end{array}$ \\
\hline
\end{tabular}

when consumers like to read entertainment content, other entertainment news will be provided. Like social media sites, when consumers post recipes, other recipes will also be posted. E-commerce provides personalization to give the information of product favored by consumers.

Information about the user's interest in something on the site can be obtained. Various methods are used to get information of consumer interest. Giving rating to something that user favors is one method to gain user interest. Some researches develop this method to get better personalization in movie website [1] or in digital newspaper [11]. In e-commerce, the consumer gives a rating on the product after purchasing the goods. Rating information and transaction information can be combined to produce product recomendation. Product recommendations produce a list of preferred and purchased products. Product recommendations can be used to provide product information to other consumers and as a solution of overload information

Another method using clickstream data. This method can provide information page visited by the user and the duration of visiting the page. Some research use this method to find user interest pattern
[12], to make a tree model of clickstream data [13], to know user activity based on user interest [14]. The purpose of that research is to improve personalization using clickstream data.

Clickstream data is user behavior information when user brows on a site. Clickstream data is stored in a weblog. Information retrieval of clickstream data is using weblog mining method. The information that can be obtained from clickstream data is the page visited by the consumer, and the duration of the visit time on the page. The page that consumers visit when shopping is the catalog that contains many products. The products favored by consumers have not been detected, it still requires transaction data and product rating data.

The proposed method to get consumer interest in product when shopping is eye tracking method. The consumer's view of the product is expressed by fixation and the duration of consumer's eye view of the product is called fixation duration. The longer the duration of the consumer's eye view of product, the bigger the consumer interest in the product [3]. Table1 show the researches that discuss consumer interest method. 
Table 2. The research with topic relation consumer interest and product selection

\begin{tabular}{|c|c|c|c|}
\hline Focus & Method & Contribution & Limitation \\
\hline $\begin{array}{l}\text { Using Framing } \\
\text { Message for stimuli } \\
\text { purchase intention } \\
\text { of consumer } \\
\text { Shu Fei Yang, } 2014 \\
{[16]}\end{array}$ & $\begin{array}{l}\text { Influence of Framing } \\
\text { Message on fixation } \\
\text { duration and purchase } \\
\text { intention }\end{array}$ & $\begin{array}{l}\text { Suggestion for e-seller how to } \\
\text { use different framing message } \\
\text { for presentation of product }\end{array}$ & $\begin{array}{l}\text { Only discuss the influence of } \\
\text { framing message to purchase } \\
\text { intention. } \\
\text { There is no calculation of purchase } \\
\text { intention }\end{array}$ \\
\hline $\begin{array}{l}\text { Using EEG and Eye } \\
\text { tracking to } \\
\text { investigate the brain } \\
\text { activity during } \\
\text { decision making } \\
\text { Rami Khushaba } \\
2013 \text { [17] }\end{array}$ & $\begin{array}{l}\text { Emotive EPOC } \\
\text { Encephalograph (EEG) } \\
\text { and Eye tracking }\end{array}$ & $\begin{array}{l}\text { The mutual information } \\
\text { analyis from EEG and Eye } \\
\text { tracking indicate that flavour } \\
\text { and topping of crackers are the } \\
\text { important factor affecting } \\
\text { buying decision compared } \\
\text { with the shape }\end{array}$ & $\begin{array}{l}\text { EEG have many wide variation data } \\
\text { for each person in each choice set } \\
\text { so the result having insuffiecient } \\
\text { EEG observation. }\end{array}$ \\
\hline $\begin{array}{l}\text { Knowing } \\
\text { relationship } \\
\text { between time spent } \\
\text { looking at } \\
\text { merchandise and } \\
\text { their likelihood to } \\
\text { buy } \\
\text { Bridget K. Behe } \\
2013 \text { [18] }\end{array}$ & $\begin{array}{l}\text { Use ETT (Eye tracking } \\
\text { Technology) and ELM } \\
\text { (Elaboration } \\
\text { Likelihood Model) }\end{array}$ & $\begin{array}{l}\text { The conclusion of this } \\
\text { research is the product visual } \\
\text { must be attractive to get the } \\
\text { attention of consumer with } \\
\text { low involvement to the } \\
\text { product. }\end{array}$ & $\begin{array}{l}\text { There is no advanced discusses } \\
\text { about price sensitivity and signage } \\
\text { on merchandise }\end{array}$ \\
\hline $\begin{array}{l}\text { Measure the } \\
\text { purchase intention } \\
\text { using eye tracking } \\
\text { data } \\
\text { Piere Chandon, } \\
2007 \text { [10] }\end{array}$ & $\begin{array}{l}\text { Use memory and visual } \\
\text { attention }\end{array}$ & $\begin{array}{l}\text { Formula to calculate purchase } \\
\text { intention }\end{array}$ & $\begin{array}{l}\text { There is no discussion about } \\
\text { implementation }\end{array}$ \\
\hline
\end{tabular}

Based on the Table 1, the relationship between visual attention and consumer preference can be detected using eye tracking method. It means eye tracking can be used to get consumer preference in a product.

\subsection{Relation of consumer interest in products with product selection}

According to Chandon in his research, the consumer interest to the product selection is influenced by memory-based factors and attentionbased factor. The memory-based factor is the knowledge and experience of the products owned by consumers and stored in memory, one of which is brand preference.

On the other hand, the attention-based factor is knowledge of products seen by consumers that make the consumers interested. Both of these, consumer interest in the products and experience in using a product or shopping experience, will affect consumers when choosing products [10].
Several studies researched the relationship between consumer interests in products with and product selection. Bialkova [2] experimented to determine the effect of user attention to nutrition on herbal products to consumer choice. Krucien [3] explored visual attention to process multi-attribute information on health programs and examined the relationship between visual attention and the selection of these health programs. Jantathai [4] did an experiment on the effects of food color on gazing behavior and examined the relationship between gazing behavior and the selection of the food. Minh [5] conducted an experiment on the effect of the food arrangement design on the gazing behavior and decision time.

Another researches also discuss about the relation of consumer interest and product selection. The research using eye tracking combined or compared with other method to get product selection. The product selection can be point to purchase intention. Some researches discuss about the stimuli 
to get purchase intention of consumer [16] and knowing the process of decission making [17].

Table 2 show the researches that discuss relation of consumer interest with product selection. The difference with Chandon, Chandon method detect purchase intention with calculate attention factor and memory factor. This method can be used to know the value of purchase intention of consumer to that product. If the value big enough it means that product is selected by consumer, and the consumer wants to buy that product.

\section{Eye tracking method}

The Eye Tracking method can be used to investigate eye movement, eye gaze on an object that is seen. The eye gaze and eye position are captured and expressed in XY coordinates and are stored in the raw data, and then the data are visualized in the fixation. The tool used for the eye tracking method is the eye tracker.

The measurement of the eye with the eye tracking method uses the following metrics:

1. Fixation is the position of the user's eyes on a product

2. The number of fixation is the number of dots of eye views on a specific area

3. Fixation duration is the length of time the user's eyes in a certain position

These metrics can be visualized in the form of eye movement saccade which is a visualization of the fixation to another fixation, while the fixation duration is visualized in the form of heat map.

\section{Measurement method of eye tracking}

Eye Tracking can be used to measure user interest in website design, and the quality of a website using the metric fixation duration. Additionally, fixation duration can also predict which products will be purchased. This section discusses consumer interest in the products using Aga Bojko and prediction of product selection using Chandon method.

\subsection{Attraction measurement}

Measurement of consumer interest in ecommerce products using the Aga Bojko method is attraction measurement which is divided into three measurements, namely area noticeable measures, areas of interest measures and emotional arousal measures.

A. Area Noticeable Measures are measure to investigate the area of interest using the following metrics: a) The percentages of users who see the AOI (Area of Interest). If this number is low, images or texts in this area need to be repaired so that they are detected quickly by the users.

b) The number of fixations to the first fixation. If this number is high, it shows that the object search process takes time, indicating that the object in these areas need to be improved to make them more visible to customers.

c) The time of the first fixation, the duration to find the desired area.

B. Areas Interest Measures are measures user interest by using metrics:

a) The number of fixation on the AOI. If this number is high, it indicates that there are many users interested. Thus, this area is very interesting.

b) The total dwell time in AOI is the number used to measure how long users pay attention to that area. It's known fixation duration.

c) The percentages of time when viewing the AOI is the result of the number of the ratio between dwell time in the AOI and the total dwell time on the web page. If the number is high, it indicates the users are interested in the AOI.

C. Emotional Arousal Measures provide emotion information about users. It can measure pupil diameter of the eye dilation. The pupil diameter enlarges when someone sees something interesting.

In this experiment, the measurement of consumer interest in product is using area noticeable measures and areas of interest measures so that the measurement of Emotional Arousal was not calculated.

\subsubsection{Experiment of Attraction Measurement}

An experiment was conducted using images from a catalog of the website of selva-house.com consisting of Muslim dress and hijabs. Participants who experimented were students of the universities in Pekanbaru, Riau, Sumatra, Indonesia. It involved 14 students. The images used on selvahouse 3 are the catalog of clothes, meanwhile the catalogs of selvahouse 5 and selvahouse 6 are hijabs as shown in Figs.2, 3, and 4. Furthermore, the software used for data retrieval is www.eyeproof.net. 


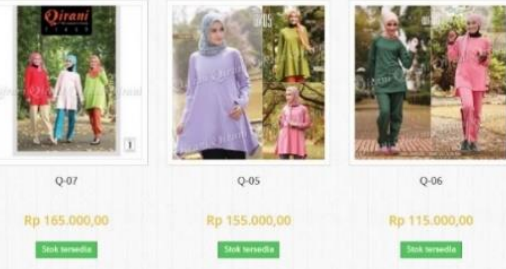

Figure.2 Catalog selvahouse 3
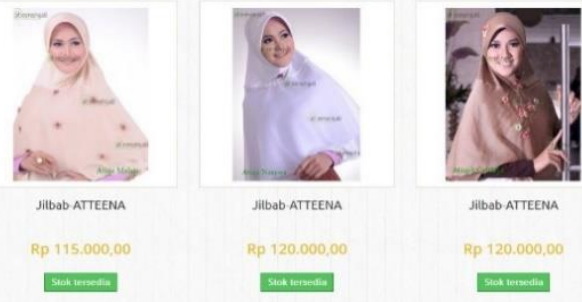

Figure.3 Catalog selvahouse5
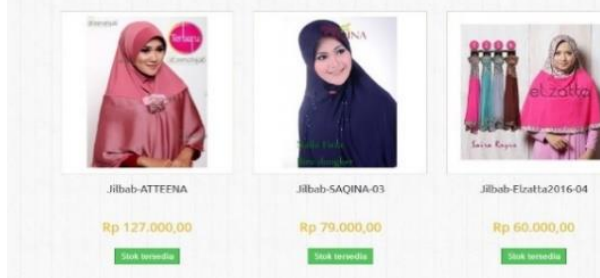

Figure.4 Catalog selvahouse6

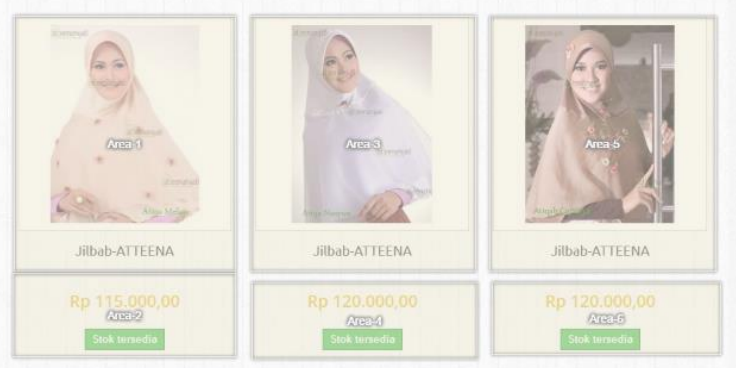

Figure.5 Area of Interest (AOI) selvahouse5
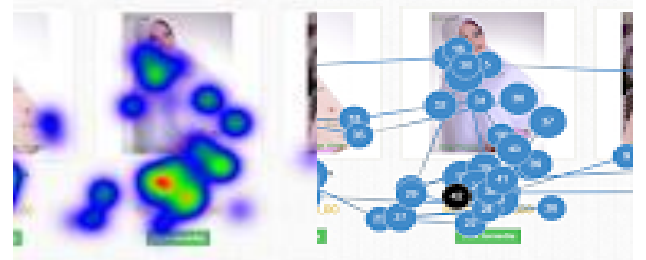

(b)

Figure.6 Heat map visualization and scan path of participants: (a) Heat Map and (b) Scan path

When the consumers conducted exploration on the cataloque of selvahouse5, eye gaze and eye movements were stored in CSV data and on each image selvahouse was specified by Area of Interest consisting of the product images, brands, and prices so that the fixation duration on the area could be calculated. The CSV data is described in Table 3. An example of the implementation of the AOI is presented in Fig. 5. The first product is indicated by $\mathrm{A} 1$ and $\mathrm{A} 2$, the second product is indicated by A3 and $\mathrm{A} 4$, and the third product is indicated by A5 and the A6.

The eye tracking data are visualized into an eye tracking heat map and scan path. The heat map visualization and scan path of participants of the selvahouse 5 image are shown in Fig. 6.

To perform an eye tracking measurements, the data of interest is calculated using the metrics below:

a. The percentages of users who see the AOI (Area of Interest).

b. Total fixation of the fixation of the first.

c. Time of the first fixation

d. Total fixation on the AOI.

e. The total dwell time in the AOI is the duration of fixation

f. The percentages of time when viewing the AOI are the results of a number of the ratio between the fixation duration on the AOI and the total fixation duration on the web page. The data of metric above is shown in Table 4.

\subsubsection{Results of attraction measurement experiment}

The next step is to calculate the consumer interest based on the following metrics. The result of eye tracking measurement of selvahouse 5 is described in Table 5:

a. The percentages of the users who see the AOI (Area of Interest).

$\mathrm{v} 1=90 \%, \mathrm{v} 2=90 \%, \mathrm{v} 3=100 \%$

The three products have high percentages, indicating that they have interesting appearances.

b. The total amount of the fixation on the first fixation.

$\mathrm{v} 1=2,5714, \mathrm{v} 2=1,3571, \mathrm{v} 3=3,64286$

The three products have a low number of fixation, indicating that the three products did not take long to be viewed by consumers.

c. Time of the first fixation

$\mathrm{v} 1=80,6 \mathrm{~ms}, \mathrm{v} 2=87,111 \mathrm{~ms}, \mathrm{v} 3=3,67 \mathrm{~ms}$

Products of v1 dan v2 have longer duration than $\mathrm{v} 3$, indicating that the consumers are more interested in $\mathrm{v} 3$, as the desired duration of finding area is low.

d. Number of the fixation on AOI. $\mathrm{v} 1=116, \mathrm{v} 2=175, \mathrm{v} 3=168$

On the product $\mathrm{v} 2$, it has more fixations than $\mathrm{v} 1$ and $v 3$, indicating that the consumers are more interested in $\mathrm{v} 2$ than the other products.

e. Total of dwell time on the AOI is the duration of the fixation.

$\mathrm{v} 1=19411 \mathrm{~ms}, \mathrm{v} 2=37693 \mathrm{~ms}, \mathrm{v} 3=33024 \mathrm{~ms}$ 
On the product of $v 2$, the fixation duration is more than $\mathrm{v} 1$ and $\mathrm{v} 3$, indicating that the consumers pay more attention to the products of v2 than other products.

f. The percentages of time when viewing the API are the results of the number of the ratio between the fixation duration on the AOI and the total fixation duration on the web page.

$\mathrm{v} 1=22 \%, \mathrm{v} 2=42 \%, \mathrm{v} 3=37 \%$

On the product of $v 2$, the percentage is higher than $\mathrm{v} 1$ and $\mathrm{v} 3$, indicating that the consumers are more interested in product of $\mathrm{v} 2$.

Table 3. The example of csv eye tracking data

\begin{tabular}{|c|c|c|c|c|c|c|c|c|c|c|}
\hline Con & FS & FD & FixX & FixY & A1 & A2 & A3 & A4 & A5 & A6 \\
\hline 0 & 11 & 298 & 730 & 327 & FALSE & FALSE & FALSE & FALSE & TRUE & FALSE \\
\hline 0 & 356 & 93 & 586 & 320 & FALSE & FALSE & TRUE & FALSE & FALSE & FALSE \\
\hline 0 & 480 & 126 & 558 & 304 & FALSE & FALSE & TRUE & FALSE & FALSE & FALSE \\
\hline 0 & 776 & 95 & 129 & 370 & FALSE & TRUE & FALSE & FALSE & FALSE & FALSE \\
\hline 0 & 1183 & 125 & 130 & 81 & TRUE & FALSE & FALSE & FALSE & FALSE & FALSE \\
\hline 0 & 1418 & 62 & 204 & 127 & TRUE & FALSE & FALSE & FALSE & FALSE & FALSE \\
\hline
\end{tabular}

\section{Description:}

Con $=$ Consumers

$\mathrm{FD}=$ Fixation Duration

A1-A6 = Area of Intererst $1-$

Area of Interest (AOI1 - AOI6)
$\mathrm{FS} \quad=$ Fixation Start

FixX $=X$ position of Fixation

FixY $=\mathrm{Y}$ position of Fixation

Table 4. The Eye Tracking Measurement of selvahouse 5

\begin{tabular}{|c|c|c|c|c|c|c|c|c|c|c|c|c|c|c|c|}
\hline \multirow[t]{2}{*}{ No } & \multirow[t]{2}{*}{ Consumer } & \multirow[t]{2}{*}{$\begin{array}{l}\text { Position } \\
\text { of First } \\
\text { Fixation }\end{array}$} & \multirow[t]{2}{*}{$\begin{array}{l}\text { Position } \\
\text { Last } \\
\text { Fixation }\end{array}$} & \multicolumn{3}{|c|}{$\begin{array}{c}\text { Number of } \\
\text { Fixation on } \\
\text { an AOI }\end{array}$} & \multicolumn{3}{|c|}{$\begin{array}{c}\text { Total dwell time on } \\
\text { an AOI }\end{array}$} & \multicolumn{3}{|c|}{$\begin{array}{c}\text { Number of } \\
\text { fixation prior } \\
\text { to first } \\
\text { fixation on an } \\
\text { AOI }\end{array}$} & \multicolumn{3}{|c|}{$\begin{array}{c}\text { Time to First } \\
\text { Fixation on an AOI }\end{array}$} \\
\hline & & & & v1 & v2 & v3 & v1 & $\mathbf{v 2}$ & v3 & v1 & v2 & v3 & v1 & v2 & v3 \\
\hline 1 & Reni & v3 & v3 & 16 & 11 & 17 & 1575 & 1459 & 2956 & 3 & 1 & 0 & 1183 & 356 & 11 \\
\hline 2 & Yuli & v2 & v3 & 4 & 22 & 8 & 888 & 4529 & 595 & 1 & 0 & 5 & 376 & 0 & 1765 \\
\hline 3 & Wenda & v2 & $\mathrm{v} 1$ & 22 & 8 & 2 & 2538 & 1967 & 205 & 2 & 0 & 3 & 11 & 685 & 1104 \\
\hline 4 & Risca & v2 & v2 & 8 & 17 & 5 & 1499 & 4392 & 1531 & 3 & 0 & 2 & 980 & 10 & 13690 \\
\hline 5 & Hazimah & v3 & v3 & 7 & 9 & 25 & 1655 & 796 & 4396 & 3 & 1 & 0 & 766 & 329 & 0 \\
\hline 6 & Fitriyana & v2 & v3 & 8 & 2 & 12 & 2011 & 237 & 3494 & 2 & 0 & 10 & 1030 & 327 & 3280 \\
\hline 7 & Puja & v1 & $\mathrm{v} 2$ & 10 & 28 & 4 & 1923 & 4375 & 595 & 0 & 3 & 5 & 11 & 1166 & 1573 \\
\hline 8 & Sheli & $\mathrm{v} 2$ & v3 & 8 & 8 & 5 & 1932 & 4678 & 799 & 3 & 0 & 5 & 1123 & 12 & 2012 \\
\hline 9 & Chenny & v1 & $\mathrm{v} 2$ & 10 & 11 & 11 & 1999 & 2739 & 2284 & 0 & 1 & 3 & 1 & 313 & 843 \\
\hline 10 & Irma & $\mathrm{v} 1$ & v3 & 11 & 3 & 29 & 1182 & 671 & 4463 & 0 & 6 & 9 & 370 & 1339 & 1980 \\
\hline 11 & Nurul & v2 & v3 & 3 & 21 & 11 & 468 & 4734 & 2340 & 4 & 0 & 3 & 1070 & 10 & 1242 \\
\hline 12 & Magfira & v1 & v2 & 4 & 11 & 14 & 754 & 2309 & 2715 & 0 & 7 & 2 & 10 & 2310 & 1092 \\
\hline 13 & Rosmah & v2 & v2 & 5 & 24 & 8 & 987 & 4717 & 1134 & 15 & 0 & 3 & 3275 & 11 & 712 \\
\hline 14 & Casie & $\mathrm{v} 2$ & v3 & 0 & 0 & 17 & 0 & 0 & 5517 & 0 & 0 & 1 & 0 & 0 & 328 \\
\hline
\end{tabular}

Table 5. The result of eye tracking measurement on selvahouse 5

\begin{tabular}{|c|c|c|c|c|c|c|}
\hline & A & B & C & D & E & F \\
\hline p1 & $90 \%$ & 2.57 & 80,6 & 116 & 19411 & $22 \%$ \\
\hline p2 & $90 \%$ & 1.36 & 87,1 & 175 & 37693 & $42 \%$ \\
\hline p3 & $100 \%$ & 3.64 & 3,67 & 168 & 33024 & $37 \%$ \\
\hline
\end{tabular}

\section{Description:}

$\mathrm{p} 1, \mathrm{p} 2, \mathrm{p} 3=$ product 1 , product 2 , product 3
A $=$ Percentage of participants who fixated on

$B=$ Number of fixation prior to first fixation on an AOI

$\mathrm{C}=$ Time to first fixation on an AOI (TTF)

$\mathrm{D}=$ Number of fixation on an AOI

$\mathrm{E}=$ Total dwell time on an AOI (fixation duration (FD))

$\mathrm{F}=$ Percentage of time spent on an AOI (Total FD on object / Total FD on homepage) 
Table 6. The result of eye tracking measurement on selvahouse 3

\begin{tabular}{|c|c|c|c|c|c|c|}
\hline & A & B & C & D & E & F \\
\hline p1 & $90 \%$ & 3.64 & 6.5 & 110 & 22671 & $22 \%$ \\
\hline p2 & $100 \%$ & 1.36 & 142,6 & 230 & 58997 & $58 \%$ \\
\hline p3 & $100 \%$ & 5.64 & 5.0 & 130 & 19716 & $19 \%$ \\
\hline
\end{tabular}

Table 7. The result of eye tracking measurement on selvahouse6

\begin{tabular}{|c|c|c|c|c|c|c|}
\hline & A & B & C & D & E & F \\
\hline p1 & $100 \%$ & 5.07 & 11.5 & 120 & 22530 & $25 \%$ \\
\hline p2 & $100 \%$ & 0.7857 & 39.63 & 165 & 35123 & $39 \%$ \\
\hline p3 & $100 \%$ & 3.7143 & 78.67 & 141 & 32999 & $36 \%$ \\
\hline
\end{tabular}

From Table 5, it can be seen that the measurements with noticeable area on metrics A and B show small difference so that all the products have an attractive appearance. However, metrics $\mathrm{C}$ shows that product 3 has the most attractive appearance. An analysis of the measurements of interest measure reveals that consumers express interest in the second product with a higher metric value than two other products.

Table 6 presents the result of the measurement of selvahouse 3 . Table 7 presents the result of the measurement of selvahouse6. Based on the measurement results, the second product is more interesting than the two other products, except for the metrics time to first fixation on an AOI, on selvahouse 3 and selvahouse 5 as the consumers find the third product with ease, meanwhile, in selvahouse 6 consumers find the first product is easier to find.

Therefore, it can be interpreted that these products already have interesting appearance that attract eyes so that consumer's first eyes go to the product. Although in the end, the consumers do not show further interest.

In conclusion, to find out whether a product has an attractive appearance or not, it can be measured by:

a. The percentages of users who see the AOI (Area of Interest)

b. Total fixation to the first fixation

c. The time of the first fixation

To figure whether consumers are interested in the product or not, the following metrics can be used:

a. Total fixation on an AOI

b. The total dwell time in AOI is the fixation duration

c. The percentages of time when viewing AOI

Consumer interest in the product will continue in the decision to select the product that will purchased. Measurements for the prediction of product purchases have been made by Chandon, with memory-based factors and attention-based factor. The calculation need fixation duration data, so in this paper to measure consumer interest only use fixation duration. The model of consumer interest with eye tracking measurement is shown in Eq. (1).

$$
F D_{A O I j}=\left\{\begin{array}{c}
\sum_{i=0}^{n} F D_{i},\left(\text { FixX }, \text { Fix } Y \text { ) in } A O I_{j}\right. \\
0,(\text { FixX }, \text { Fix } Y) \text { not in } A O I_{j}
\end{array}\right.
$$

where $j=1,2,3, \ldots . \mathrm{m} \quad$ ( a number of AOI)

$F D_{A O I j}$ is Fixation Duration in Area of Interest of $\mathrm{j}$. $F D_{A O I j}$ depends on condition of the position of consumer view to product (FixX, FixY). If (FixX,FixY) in $\mathrm{AOI}_{\mathrm{j}}$ then fixation duration is totaled.

\subsection{Prediction measurement}

A study conducted by Chandon [10] about the prediction of product selection using the eye tracking method to predict consumer desires. The memory of the product and attention become the consideration aspects in the prediction of product selection. Chandon uses variable $\beta$ for probability assessment of the product by consumers and variable $\alpha$ for attention, in this case, the probability of eye fixation. $\beta$ value depends on consumer experience or consumer opinion of product and the value is between 0 and $1(0 \leq \beta \leq 1)$. When $\beta=0$, it means consumer doesn't have experience with the product or consumer has negatif feeling to that product. The opposite, when $\beta=1$, it means consumer have good experience with the product or consumer has positif feeling to that product. In this experiment, $\beta$ value is set constant, which is 0.01 , because the objective of this research is to analyze the value $\alpha$ and its influence to prediction value. The equation for prediction of selection product is shown in Eq. (2).

$$
\begin{gathered}
C=\frac{\sum_{i=0}^{n} 0.01+0.0099 \alpha+0.0098 \alpha^{2}}{n} \\
\text { where } \alpha=\frac{F D_{A O I}}{\sum_{j=0}^{m} F D_{A O I}}
\end{gathered}
$$

\subsubsection{The experiment of prediction measurement}

The experiments prediction of measurement used the website of the selva-house consisting of three products of hijabs shown in Fig. 2, uses Eq. (2) to find the predicted value. The $\alpha$ value is the probability of FD (fixation duration) on the product, while the value of $\beta$ is assumed to 0.01 . The example of result this experiment is shown in Table 8. 
To find the maximum prediction between the three products, the predicted values are categorized by the product into $\mathrm{C} 1, \mathrm{C} 2$ and $\mathrm{C} 3$ as shown in Table 6. $\mathrm{C} 1$ for the first product, $\mathrm{C} 2$ for the second product and C3 for the third product. Predicted value converted to predictive level of the product selection, the higher the value means the product will most likely be selected. Based on the results that shown in Table 9, there are some products in level 4. Product that has the most value 4 is the second product. Besides that, several consumers are also predicted to choose the first product and the third product. The result of product selection prediction is shown in Table 10.

Table 8. An example of the measurement of the prediction of products selection on Selvahouse5

\section{Description:}

\begin{tabular}{|c|r|r|r|r|r|r|}
\hline Con & \multicolumn{1}{c|}{ P } & \multicolumn{1}{|c|}{ FC } & \multicolumn{1}{|c|}{ FD } & $\boldsymbol{\alpha}$ & $\boldsymbol{\beta}$ & $\boldsymbol{C}$ \\
\hline 0 & 3 & 1 & 298 & 0.049749583 & 0.01 & 0.010516781 \\
\hline 0 & 2 & 1 & 93 & 0.015525876 & 0.01 & 0.010156039 \\
\hline 0 & 2 & 2 & 126 & 0.021035058 & 0.01 & 0.010212584 \\
\hline 0 & 1 & 1 & 95 & 0.015859766 & 0.01 & 0.010159479 \\
\hline 0 & 1 & 2 & 125 & 0.020868114 & 0.01 & 0.010210862 \\
\hline 0 & 1 & 3 & 62 & 0.010350584 & 0.01 & 0.010103521 \\
\hline
\end{tabular}

$$
\begin{array}{ll}
\text { Con } & =\text { Consumer } \\
\mathrm{P} & =\text { Hijab products } \\
\mathrm{FC} & =\text { Count Fixation } \\
\mathrm{FD} & =\text { Fixation Duration } \\
\alpha & =\text { Probabilistic value of fixation duration } \\
6 & =\text { Brand preference } \\
\mathrm{C} & =\text { Consideration (the predicted value of the product to be purchased) }
\end{array}
$$

The rule levels are as follows:

\begin{tabular}{|c|c|c|c|c|c|c|}
\hline \multirow[b]{2}{*}{ Con } & \multicolumn{3}{|c|}{ Prediction of product selection } & \multicolumn{3}{|c|}{ Level } \\
\hline & C1 & $\mathrm{C} 2$ & C3 & LC1 & $\mathrm{LC} 2$ & LC3 \\
\hline 1 & 0.003318 & 0.002616 & 0.003608 & 3 & 2 & 3 \\
\hline 2 & 0.001473 & 0.006223 & 0.001743 & 1 & 4 & 1 \\
\hline 3 & 0.006952 & 0.002724 & 0.000659 & 4 & 2 & 0 \\
\hline 4 & 0.002737 & 0.005539 & 0.001739 & 2 & 4 & 1 \\
\hline 5 & 0.001813 & 0.00128 & 0.005916 & 1 & 1 & 4 \\
\hline 6 & 0.00335 & 0.000474 & 0.00484 & 3 & 0 & 3 \\
\hline 7 & 0.002211 & 0.006107 & 0.000735 & 2 & 4 & 0 \\
\hline 8 & 0.00346 & 0.00465 & 0.002432 & 3 & 3 & 2 \\
\hline 9 & 0.00228 & 0.003564 & 0.00323 & 2 & 3 & 3 \\
\hline 10 & 0.002089 & 0.000707 & 0.005848 & 2 & 0 & 4 \\
\hline 11 & 0.000875 & 0.005616 & 0.003234 & 0 & 4 & 3 \\
\hline 12 & 0.001333 & 0.002717 & 0.004028 & 1 & 2 & 3 \\
\hline 13 & 0.001288 & 0.005431 & 0.001792 & 1 & 4 & 1 \\
\hline 14 & 0 & 0 & 0.008214 & 0 & 0 & 4 \\
\hline
\end{tabular}

If $\mathrm{C}<0.001$ : level 0 ,

If $\mathrm{C}>=0.001$ and $\mathrm{C}<0.002$ : level 1

If $\mathrm{C}>=0.002$ and $\mathrm{C}<0.003$ : level 2

If $\mathrm{C}>=0.003$ and $\mathrm{C}<0.005$ : level 3

If $\mathrm{C}>=0.005$ : level 4

Table 9. The result of the measurement of the prediction of the product 1,2 dan 3

\section{Description:}

\section{Con = Consumer}

$\mathrm{C} 1-\mathrm{C} 3=$ Value of purchase intention to the product 1-3

LC1-LC2 $=$ Level of purchase intention to the product 1-3 
Table 10. The result of product selection prediction

\begin{tabular}{|c|c|}
\hline Consumer & Product \\
\hline 2 & second product \\
\hline 3 & first product \\
\hline 4 & second product \\
\hline 5 & third product \\
\hline 7 & second product \\
\hline 10 & third product \\
\hline 11 & second product \\
\hline 13 & second product \\
\hline 14 & third product \\
\hline
\end{tabular}

The data in Table 10 can be assumed as transaction data. Consumer 2, 4, 7, 11, 13 buy the second product, consumer 5,10,14 buy the third product and consumer 3 buys the first product

This study yields consumer interest data and predictive data for product selection. Both data can be used to product recommendation. Further research is to discuss about product recommendation using eye tracking method

\section{Discussion and conclusion}

Measurement of consumer interest in the product can be observed using eye tracking method. In Aga Bojko taxonomy of eye tracking measurements, there is the attraction of measurement that investigates the initial interest in that area, investigates the user's interest in the area and investigates how emotions of users in that area. This method can be used to investigate whether a product has an interesting appearance and whether a product is preferred by consumers.

After conducting experiments and measurements of consumer interest in the products using metrics on area noticeable measure and areas of interest measures, it can be seen that the second product is preferred by consumers. Although at one metric area noticeable measure states that the second product does not have an interesting appearance. Thus, it can be concluded that the preferred product by the consumers does not necessarily have an interesting appearance, as there are several other factors that make consumers prefer the product.

Metric measuring consumer interest in the products is the fixation duration that can be used to determine the prediction of product selection. The Chandon method calculates the predictions by considering the brand preference and attention. The results of the experiments reveal that the second product is a product that selected by most consumers.

The results of both experiments, measuring the consumer interest in the product and the prediction of product selection by consumer produce the same product that is the second product. It can be concluded that the consumer interest in the product and the prediction of product selection by consumer have a relation, this is the contribution of this research beside the model mathematic of consumer interest and prediction of product selection.

The results of the product selection prediction measurements in Table 9 show that each consumer is interested in a particular product with various prediction levels selected. This data can be used for product recommendations. Product recommendation is one of the methods of personalization to provide convenience to consumers in choosing products that purchased by other consumers. Further research can examine product recommendations which are based on products that consumers prefer based on product selection predictions using the eye tracking technology.

\section{Acknowledgments}

This work was supported by RisteDikti of the Ministry of Research and Higher Education of the Republic of Indonesia under Doctoral Research Grant.

\section{References}

[1] X. Zhao, Z. Niu, and W. Chen, "Interest before liking: Two-step recommendation approaches", Knowledge-Based Systems, Vol.48, pp.46-56, 2013.

[2] S. Bialkova, K. G. Grunert, H. Jørn, G. Wasowicz-kirylo, M. Stysko-kunkowska, and H. C. M. Van Trijp, "Attention mediates the effect of nutrition label information on consumers' choice. Evidence from a choice experiment involving", Appetite, Vol.76, pp.66-75, 2014.

[3] N. Krucien, M. Ryan, and F. Hermens, "Visual attention in multi-attributes choices: What can eye-tracking tell us?", Journal of Economic Behavior \& Organization, Vol.135, pp. 251-267, 2017.

[4] S. Jantathai, L. Danner, M. Joechl, and K. Dürrschmid, "Gazing behavior, choice and color of food : Does gazing behavior predict choice ?", Food Research International, Vol.54, No.2, pp.1621-1626, 2013.

[5] T. Minh, H. Vu, V. Phu, and K. Duerrschmid, "Design factors influence consumers' gazing behaviour and decision time in an eye-tracking test: A study on food images", Food Quality Preference, Vol.47, pp.130-138, 2016.

[6] I. Krajbich, D. Lu, C. Camerer, and A. Rangel, "The attentional drift-diffusion model extends to 
simple purchasing decisions", Frontriers in Psychology, Vol.3, 2012.

[7] J. N. Sari, R. Ferdiana, P. I. Santosa, and L. E. Nugroho, "An Eye Tracking Study : Exploration Customer Behavior on Web Design", In: Proc. of the International HCI and UX Conference, Bandung, Indonesia, pp.69-72, 2015.

[8] A. Bojko, "Eye Tracking the User Experience", Rosefeld, 2013.

[9] J. N. Sari, H. A. Nugroho, L. E. Nugroho, P. I. Santosa, and R. Ferdiana, "A Study on Algorithms of Pupil Diameter Measurement", In: Proc. of the 2nd International Conference on Science and Technology-Computer, Jogjakarta, pp.1-5, 2016.

[10] P. Chandon, J. W. Hutchinson, E. T. Bradlow, and S. H. Young, "Measuring the value of pointof-purchase marketing with commercial eyetracking data", INSEAD Business School Research Paper, No.22, p.55, 2007

[11] S. Cleger-tamayo, J. M. Fernández-luna, and J. F. Huete, "Top- $\mathrm{N}$ news recommendations in digital newspapers", Knowledge-Based Systems, Vol.27, pp.180-189, 2012.

[12] Q. Su and L. Chen, "A method for discovering clusters of e-commerce interest patterns using click-stream data", Electronic Commerce Research and Applications, Vol.14, No.1, pp.113, 2015.

[13] S. , G. Öğüdücü and M. T. Özsu, "Incremental click-stream tree model: Learning from new users for web page prediction", Distributed and Parallel Databases, Vol.19, pp.5-27, 2006.

[14] J. Zeng, S. Zhang, and C. Wu, "A framework for WWW user activity analysis based on user interest", Knowledge-Based Systems, Vol.21, No.8, pp. 905-910, 2008.

[15] P. Chynal, J. Sobecki, and M. Rymarz, "Shopping Behaviour Analysis using Eyetracking and EEG", In: Proc. of the 9th International Conference on Human System Interactions, pp.458-464, 2016.

[16] S. Yang and H. Lin, "Effects of Attribute Framing Varying with the Elaboration in Online Shopping: An Eye-Track ing Approach", In: Proc. of the 47th Hawaii International Conference on Systems Science, pp.3083-3092, 2014.

[17] R. N. Khushaba, C. Wise, S. Kodagoda, J. Louviere, B. E. Kahn, and C. Townsend, "Expert Systems with Applications Consumer neuroscience: Assessing the brain response to marketing stimuli using electroencephalogram ( EEG ) and eye tracking”, Expert System with Application, Vol.40, No.9, pp3803-3812, 2013
[18] B. K. Behe, J. Zhao, L. Sage, P. T. Huddleston, and S. Minahan, "Display signs and involvement: the visual path to purchase intention", Journal International Review of Retail Distribution Consumer Research, Vol.23, No.5, pp.511-522, 2013. 